Research Paper

\title{
Etomidate Anesthesia during ERCP Caused More Stable Haemodynamic Responses Compared with Propofol: A Randomized Clinical Trial
}

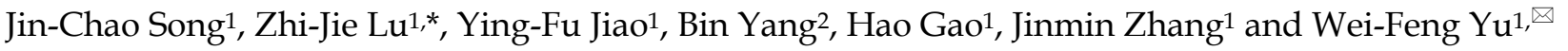 \\ 1. Department of Anesthesiology, Eastern Hepatobiliary Surgery Hospital, Second Military Medical University, Shanghai, China \\ 2. Department of Anesthesiology, Shanghai first people's hospital, Shanghai Jiao Tong University School of Medicine, Shanghai, China \\ ${ }^{*}$ Contributed equally to this work
}

$\square$ Corresponding author: Wei-Feng Yu, Department of Anesthesiology, Eastern Hepatobiliary Surgery Hospital, Second Military Medical University, Changhai Rd., No. 225, Shanghai, China. E-mail: ywf808@sohu.com. Tel and fax: +86 2181875231

(C) 2015 Ivyspring International Publisher. Reproduction is permitted for personal, noncommercial use, provided that the article is in whole, unmodified, and properly cited. See http://ivyspring.com/terms for terms and conditions.

Received: 2015.01.07; Accepted: 2015.05.25; Published: 2015.07.03

\begin{abstract}
Background: Propofol may result in hypotension and respiratory depression, while etomidate is considered to be a safe induction agent for haemodynamically unstable patients because of its low risk of hypotension. We hypothesized that etomidate anesthesia during ERCP caused more stable haemodynamic responses compared with propofol. The primary endpoint was to compare the haemodynamic effects of etomidate vs. propofol in ERCP cases. The secondary endpoint was overall survival.

Methods: A total of 80 patients undergoing ERCP were randomly assigned to an etomidate or propofol group. Patients in the etomidate group received etomidate induction and maintenance during ERCP, and patients in the propofol group received propofol induction and maintenance. Cardiovascular parameters and procedure-related time were measured and recorded during ERCP.

Results: The average percent change to baseline in MBP was $-8.4 \pm 7.8$ and $-14.4 \pm 9.4$ with $P=$ 0.002 , and in $H R$ was $1.8 \pm 16.6$ and $2.4 \pm 16.3$ with $P=0.874$ in the etomidate group and the propofol group, respectively. MBP values in the etomidate group decreased significantly less than those in the propofol group $(P<0.05)$. The ERCP duration and recovery time in both groups was similar. There was no significant difference in the survival rates between groups $(p=0.942)$.

Conclusions: Etomidate anesthesia during ERCP caused more stable haemodynamic responses compared with propofol.
\end{abstract}

Key words: Etomidate anesthesia, propofol

\section{Introduction}

Over the last few years, there has been growing interest in the use of propofol in endoscopic procedures. However, propofol may result in hypotension, respiratory depression, and loss of protective reflexes. It is extremely important to ensure the patient's clinical stability during endoscopic procedures.[1] Most patients who need ERCP suffer from obstructive jaundice. Patients with obstructive jaundice are prone to develop hypotension and bradycardia during anesthesia induction and maintenance compared with nonjaundiced patients.[2-4] Etomidate is a nonbarbiturate hypnotic that induces anesthesia through GABA receptors in the central nervous system.[5] Etomidate is considered to be a safe induction agent for haemodynamically unstable patients because of its low risk of hypotension.[6, 7] Etomidate for proce- 
dural sedation has been used in emergency departments for many years. [8-10] Recently, it was reported that etomidate for sedation during colonoscopy resulted in more stable haemodynamic responses and shorter recovery and discharge times compared with propofol.[11] However, there are some conflicting results on the adverse effect of etomidate on adrenocortical suppression. One recent paper compared much larger numbers of patients given etomidate and propofol, and found that etomidate was associated with an increased risk of 30-day mortality, cardiovascular morbidity, and prolonged hospital stay [12], while another systematic review showed that etomidate suppressed adrenal function transiently without demonstrating a significant effect on mortality.[13]

In the present study, we hypothesized that etomidate anesthesia during ERCP causes more stable haemodynamic responses compared with propofol. The primary endpoint was to compare the haemodynamic effects of etomidate vs. propofol in ERCP cases. The secondary endpoint was overall survival. Overall survival was defined as the interval between treatment and death of any cause.

\section{Methods}

This study was approved by the Committee on Ethics of Biomedicine Research, Eastern Hepatobiliary Surgery Hospital (EHBHKY-2013-002-003) prior to its start. The registration number of randomized clinical trials is ChiCTR-TRC- 13003850 (The URL is http://www.chictr.org/cn/. The name of the principal investigator is Jinchao Song). A total of 80 ASA I-III patients undergoing ERCP, aged 18-70 years and weighing $45-90 \mathrm{~kg}$, were enrolled in this study. Written consent was obtained from all subjects. Patients with known adrenocortical insufficiency, chronic sedative or opioid analgesic use, known allergy to the study drugs, heart failure (ejection fraction $<40 \%$ ), and/or severe respiratory disease (vital capacity and/or forced expiratory volume $<50 \%$ ) preoperatively were excluded from this study. The patients were computer-randomized into either the etomidate group or the propofol group. The patients, gastroenterologists, anesthesiologist assistant and nurses in the recovery room were blinded to the grouping. The anesthesiologist assistant observed and recorded vital signs through a local area network in the next room.

All patients were premedicated with an intramuscular injection of $100 \mathrm{mg}$ pethidine twenty minutes before entering the endoscopy room. BIS (BIS ${ }^{\mathrm{TM}} \mathrm{XP}$ sensor), noninvasive blood pressure, heart rate (HR), ECG and peripheral oxygen saturation $\left(\mathrm{SpO}_{2}\right)$ were monitored continuously throughout the study in the endoscopy room (Philips HP Viridia 24/26 M1205A). A 20-gauge intravenous cannula was placed in the peripheral vein for $0.9 \%$ normal saline infusion and drugs. The BIS sensor (BISTM XP) was applied according to the manufacturer's recommendations. Oxygen was administered at a rate of 5 $\mathrm{L} / \mathrm{min}$ by nasal catheter during ERCP. All the patients underwent ERCP in the prone position without tracheal intubation. After recovery, 50-100mg of pethidine was given, if necessary.

Baseline values of mean arterial blood pressure (MBP) were measured at 5 minutes after the patient entered the endoscopy room. Then, all patients received 2-2.5 mg midazolam (IV). After 5 minutes, induction was started. In the etomidate group, etomidate was delivered at a rate of $30 \mu \mathrm{g} \bullet \mathrm{kg}^{-1} \bullet \mathrm{min}^{-1}$ by a Graseby 3500 syringe pump (SIMS Graseby Ltd., Herts, England) until the BIS was 50, then ERCP was started. Anesthesia was maintained with etomidate $\left(8-12 \mu \mathrm{g} \bullet \mathrm{kg}^{-1} \bullet \mathrm{min}^{-1}\right)$ during ERCP. In the propofol group, propofol was delivered at a rate of 0.3 $\mathrm{mg} \bullet \mathrm{kg}^{-1} \bullet \mathrm{min}^{-1}$ until the BIS was 50, and anesthesia was maintained with propofol $(0.12-0.18$ $\left.\mathrm{mg} \bullet \mathrm{kg}^{-1} \bullet \mathrm{min}^{-1}\right)$. BIS was used to monitor the depth of anesthesia during the ERCP operation, and controlled at about 50 by fine-adjusting anesthetic agents. Emergency equipment was available throughout the ERCP procedure. Dopamine $\left(2-5 \mu \mathrm{g} \bullet \mathrm{kg}^{-1} \bullet \mathrm{min}^{-1}\right)$ or an appropriate dose of metaraminol was given once MBP fell below $60 \mathrm{mmHg}$, and $0.25 \mathrm{mg}$ atropine was given once HR fell below $50 \mathrm{bpm}$. Appropriate nitroglycerin was given once MBP rose above $120 \mathrm{mmHg}$, and appropriate esmolol was given once HR rose above $120 \mathrm{bpm}$. If spontaneous ventilation was insufficient $\left(\mathrm{SpO}_{2}<92 \%\right)$, the anesthesiologist performed assisted mask ventilation as necessary. If myoclonus was observed in the etomidate group, 50-100mg propofol was given and propofol took the place of etomidate in anesthesia maintenance. ERCP procedures were performed in a standardized manner under the supervision of two experienced gastroenterologists.

$\mathrm{MBP}, \mathrm{HR}, \mathrm{SpO}_{2}$ were measured and recorded at the designated time points: $\mathrm{T}_{0}=$ baseline values, $5 \mathrm{~min}$ after entering the endoscopy room; $\mathrm{T}_{1}=5 \mathrm{~min}$ after the patients received midazolam; $\mathrm{T}_{2}=$ when BIS was 50 (after induction of etomidate or propofol); $\mathrm{T}_{3}=$ at scope intubation and $\mathrm{T}_{4-10}=$ by 5-min intervals during the ERCP. The induction time, duration of ERCP and recovery time were recorded.

The patient's satisfaction with the procedure $(1=$ unacceptable, 2 = extremely uncomfortable, $3=$ slightly uncomfortable, $4=$ no discomfort) was assessed 1 hour after ERCP. The gastroenterologist's satisfaction was assessed immediately after ERCP as: 1, poor; 2, fair; 3, good; 4, excellent.[14]

Clinical signs of adrenocortical suppression such 
as hypotension and arrhythmia were monitored carefully after ERCP since etomidate may transiently cause adrenal suppression. After ruling out the general reason of hypotension and arrhythmia, we may consider adrenocortical suppression in etomidate group. Hydrocortisone (200-300 mg per day) was given if necessary.

The primary endpoint was the average percent change to baseline in mean arterial pressure and heart rate. Percent change $=\left(\mathrm{MBP}_{\mathrm{T} 1-10}-\mathrm{MBP}_{\mathrm{T} 0}\right) / \mathrm{MBP}_{\mathrm{T} 0}$ * 100. The secondary endpoint was overall survival. Overall survival was defined as the interval between treatment and death of any cause.

The group sample size was calculated based on the result of a pilot study, in which we found that the average percent change to baseline in mean arterial pressure was $-7.5 \pm 8.3(\mathrm{n}=12)$ in the etomidate group and $-13.5 \pm 10.3(\mathrm{n}=12)$ in the propofol group. 38 samples for each group met the requirement of $a=$ 0.05 and power $=0.8 .[15]$

All data in the text and tables are expressed as mean $\pm S D$, number (n) or percentage. Continuous outcomes with normal distribution were analyzed with independent 2-sample t-test. The count data were compared using the $\chi^{2}$ test or Fisher's exact test or Continuity correction where appropriate. Reported $P$ value was 2 -sided, with $P<0.05$ considered statistically significant. The Kaplan-Meier estimate was used in survival analysis. All analyses were conducted using SPSS 17.0 (SPSS Inc., Chicago, IL). Figures were made using GraphPad Prism 5.

\section{Results}

The study was completed without any significant clinical complication. There was no statistical significance between characteristics of patients such as gender, age, body height, weight or diagnosis (Table 1).

The average percent change to baseline MBP was $-8.4 \pm 7.8$ and $-14.4 \pm 9.4$ with $P=0.002$, and average percent change to baseline HR was $1.8 \pm 16.6$ and $2.4 \pm 16.3$ with $P=0.874$ in the etomidate group and the propofol group, respectively. MBP values in the etomidate group decreased significantly less than those in the propofol group $(\mathrm{P}<0.05)$. Figure 1,2 shows the time course of percent change to baseline in mean arterial pressure and heart rate. Figure 3 shows the $\mathrm{SpO}_{2} \%$ levels over the designated time points.

Induction time was longer in the etomidate group $(\mathrm{P}<0.05)$, but there was no statistical significance between groups for ERCP duration and recovery time $(P>0.05)$ (Table 2$)$. There was no statistical significance between groups for patient satisfaction and gastroenterologist satisfaction $(\mathrm{P}>0.05)$ (Table 2). The mean hospital stay was 8.7 days in the etomidate group vs. 8.6 days in the propofol group (n.s.).

All adverse events during and after ERCP are presented in Table 3 . There was significantly more injection site pain in the propofol group $(\mathrm{P}<0.05)$.

There was no significant difference in the survival rates between groups $(p=0.942)$.

Table 1. Patient Characteristics and Pre-operative Laboratory Values.

\begin{tabular}{llll}
\hline & $\begin{array}{l}\text { Etomidate group } \\
(\mathrm{n}=40)\end{array}$ & $\begin{array}{l}\text { Propofol group } \\
(\mathrm{n}=40)\end{array}$ & $P$ \\
\hline Gender, M/F & $28 / 12$ & $28 / 12$ & - \\
Age, yr & $55.8 \pm 10.6$ & $52.4 \pm 11.4$ & 0.172 \\
Body height, $\mathrm{cm}$ & $164.8 \pm 8.6$ & $164.1 \pm 8.3$ & 0.762 \\
Weight, kg & $62.4 \pm 11.4$ & $63.5 \pm 11.8$ & 0.709 \\
Bilirubin, $\mu \mathrm{mol} / \mathrm{L}$ & $118.2 \pm 117.8$ & $108.2 \pm 142.2$ & 0.748 \\
WBC, $\times 10^{9} / \mathrm{L}$ & $5.2 \pm 1.7$ & $5.9 \pm 2.0$ & 0.126 \\
ASA $(\mathrm{I} / \mathrm{II} / \mathrm{III})$ & $18 / 15 / 7$ & $17 / 16 / 7$ & - \\
Benign disease, $\mathrm{n}$ & 22 & 23 & - \\
Malign disease, $\mathrm{n}$ & 18 & 17 & - \\
\hline
\end{tabular}

Data are expressed as Mean \pm SD or number of patients. ASA, American Society of Anesthesiologists. Malign disease includes mainly Carcinoma of head of pancreas, Gallbladder Carcinoma, Hilar bile duct cholangiocarcinomas, Carcinoma in the middle and distal bile duct, and Intrahepatic bile duct cholangiocarcinomas. Benign disease includes mainly Intrahepatic bile duct stone, Choledocholithiasis, and Common bile duct stricture.

Table 2. Procedure-related time, satisfaction. and hospital stay

\begin{tabular}{llll}
\hline & $\begin{array}{l}\text { Etomidate } \\
\text { group } \\
(\mathrm{n}=40)\end{array}$ & $\begin{array}{l}\text { Propofol group } P \\
(\mathrm{n}=40)\end{array}$ \\
\hline Induction time (min) & $5.6 \pm 0.8$ & $5.2 \pm 0.9$ & $\mathbf{0 . 0 3 7}$ \\
Duration of ERCP (min) & $20.9 \pm 8.4$ & $20.4 \pm 9.2$ & 0.800 \\
Recovery time (min) & $14.5 \pm 9.3$ & $15.2 \pm 6.1$ & 0.702 \\
Patient satisfaction & $3.8 \pm 0.4$ & $3.8 \pm 0.3$ & 0.419 \\
Gastroenterologist satisfaction & $3.8 \pm 0.4$ & $3.8 \pm 0.4$ & 1.000 \\
Hospital stay (days) & $8.7 \pm 3.6$ & $8.6 \pm 3.3$ & 0.856 \\
\hline
\end{tabular}

Data are expressed as Mean \pm SD. Induction time (the time from starting propofol/etomidate to BIS $=50$ ), Duration of ERCP (the time from scope intubation to scope withdrawal), and Recovery time (the time from stopping the drugs to full recovery (modified Aldrete score of 10)).

Table 3. Adverse events

\begin{tabular}{lllll}
\hline & & $\begin{array}{l}\text { Etomidate } \\
\text { group } \\
\mathrm{n}(\%)\end{array}$ & $\begin{array}{l}\text { Propofol } \\
\text { group } \\
\mathrm{n}(\%)\end{array}$ & $P$ \\
\hline During ERCP & Desaturation & 0 & 0 & - \\
& Apnoea & 0 & 0 & - \\
& Hypotension & $1(2.5)$ & $1(2.5)$ & 1.000 \\
& Bradycardia & 0 & 0 & - \\
& Hypertension & $2(5)$ & $1(2.5)$ & 1.000 \\
& Tachycardias & $4(10)$ & $6(15)$ & 0.499 \\
& Nausea-vomiting & $1(2.5)$ & $1(2.5)$ & 1.000 \\
& Myoclonus & $1(2.5)$ & 0 & 1.000 \\
& Injection site pain & 0 & $6(15)$ & $\mathbf{0 . 0 3 4}$ \\
& Pancreatitis & 0 & 0 & - \\
& Cholangitis & $1(2.5)$ & $2(5)$ & 1.000 \\
& Sepsis & 0 & 0 & - \\
& Adrenal crisis & 0 & 0 & - \\
\hline
\end{tabular}

Data are expressed as percentage. Desaturation (oxygen saturation $<90 \%$ for $>10$ seconds); Apnoea (cessation of respiratory activity for over 10 seconds); Hypotension (MBP $<60 \mathrm{mmHg}$ or decreases more than $25 \%$ from the baseline); Bradycardia (HR $<50 \mathrm{bpm}$ ); Tachycardias was defined as HR $>120 \mathrm{bpm}$ in this study. Hypertension was defined as MBP $>120 \mathrm{mmHg}$. 


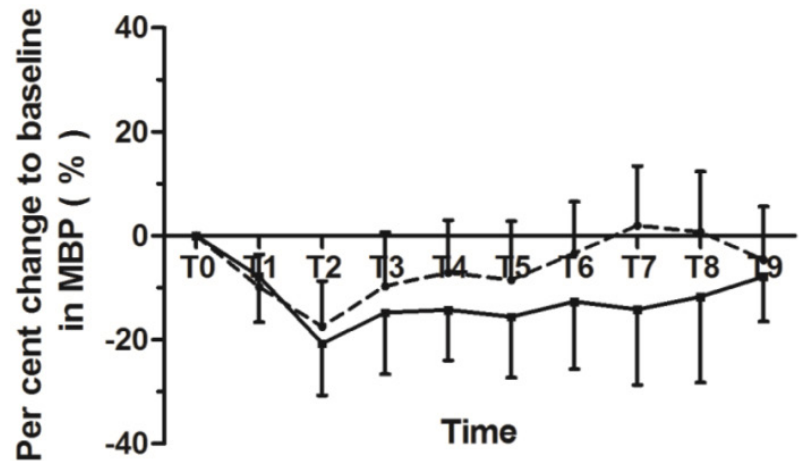

Figure 1. The time course of percent change to baseline in mean arterial pressure. $T_{0}=$ baseline values; $T_{1}=$ at 5 min after the patients received midazolam; $\mathrm{T}_{2}=$ when $\mathrm{BIS}$ was 50 after induction; $\mathrm{T}_{3}=$ at scope intubation; $\mathrm{T}_{4-10}=$ by 5 -min intervals during the ERCP.

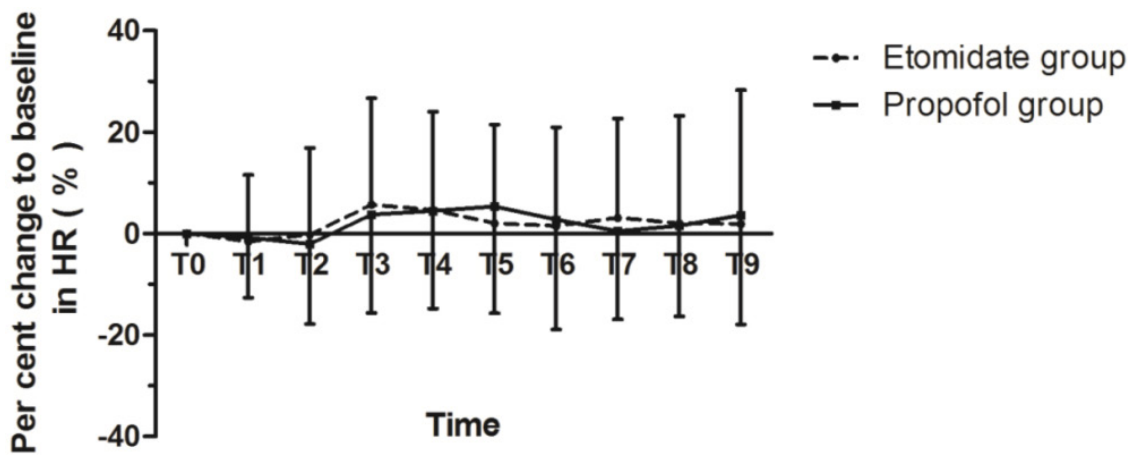

Figure 2. The time course of percent change to baseline in heart rate. $T_{0}=$ baseline values; $T_{1}=$ at 5 min after the patients received midazolam; $T_{2}=$ when BIS was 50 after induction; $T_{3}=$ at scope intubation; $T_{4-10}=$ by 5 -min intervals during the ERCP.

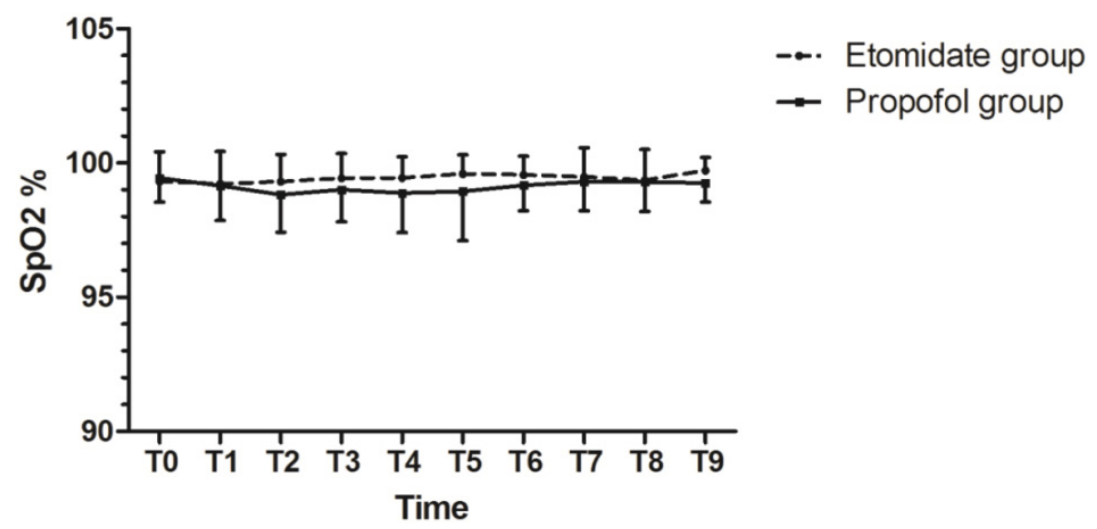

Figure 3. The $\mathrm{SpO}_{2} \%$ levels over the designated time points. $\mathrm{T}_{0}=$ baseline values; $\mathrm{T}_{1}=$ at $5 \mathrm{~min}$ after the patients received midazolam; $\mathrm{T}_{2}=$ when $\mathrm{BIS}$ was 50 after induction; $T_{3}=$ at scope intubation; $T_{4-10}=$ by 5 -min intervals during the ERCP.

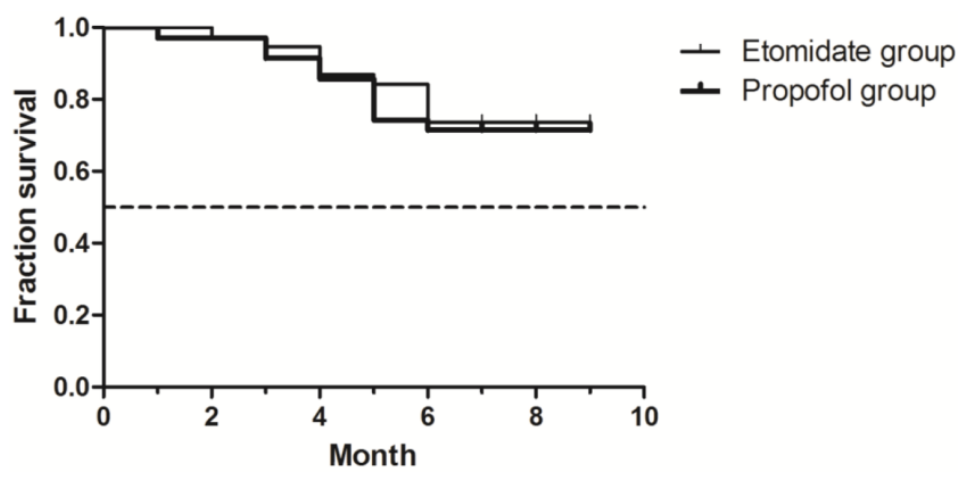

Figure 4. Survival analysis. Overall survival was defined as the interval between treatment and death of any cause. 


\section{Discussion}

In the present study, we investigated the influence of etomidate and propofol on haemodynamics in patients who underwent ERCP. The results showed that etomidate anesthesia during ERCP caused more stable haemodynamic responses compared with propofol.

In our endoscopy center, as a rule, the patients underwent ERCP in the prone position without tracheal intubation. It is known that the prone position may lead to inhibition of breathing because of airway obstruction. To reduce the incidence of respiratory depression caused by opioid agents, patients received pethidine pretreatment $(100 \mathrm{mg}$ i.m.) instead of intravenous opioids. The absorption of intramuscular injection of drugs may be irregular and a confounding factor to the hemodynamic stability. Patients in both groups received pethidine pretreatment, therefore, the analgesia level could be comparable between two groups. In the present study, no patient experienced desaturation or apnoea, and the incidence of respiratory depression was much lower than in the other reports.[11] There are at least two factors that may help explain this. First, the low incidence of respiratory depression primarily due to the normal BMI in the studied Chinese patients. Secondly, patients with known severe respiratory disease (vital capacity and/or forced expiratory volume $<50 \%$ ) were excluded from this study. There were not enough data in obese patients and in patients with severe respiratory disease. Therefore, we must be careful of hypoxia during ERCP under the general anesthesia without tracheal intubation in these patients. New techniques, such as supraglottic jet oxygenation and ventilation, can be used to minimize hypoxia/hypercapnia during ERCP under infusion of etomidate or propofol in these patients.[16]

It has been known that sedation and anesthesia are routinely required during ERCP [17-19], because ERCP is a complex endoscopic procedure requiring a high level of patient cooperation. Various types of sedative and analgesic techniques have been used during ERCP procedure. It is generally accepted among gastroenterologists that propofol is a good hypnotic with rapid onset, rapid recovery, and minimal side effects. $[17,18,20]$ It was reported that a target-controlled infusion system for administration of propofol provided safe and effective sedation during ERCP.[21] In a pilot study, it was shown that patient-maintained sedation with TCI propofol was safe and fully effective in 16 patients.[22] However, it was reported in a guideline of sedation and anesthesia in GI endoscopy that transient hypotension occurs in $4 \%$ to $7 \%$ of cases using propofol sedation and transient hypoxia occurs in 3\% to $7 \%$ of cases.[23]

Etomidate is a nonbarbiturate hypnotic that induces anesthesia through GABA receptors in the central nervous system.[5] It has a rapid onset of action $(\leq 1$ minute) and a short duration of action (3-5 minutes). According to Miller's Anesthesia, "The properties of etomidate include haemodynamic stability, minimal respiratory depression, cerebral protection, and pharmacokinetics enabling rapid recovery after a single dose".[24] Etomidate's haemodynamic stability may be due to its unique lack of effect on the sympathetic nervous system and on baroreceptor function.[25]

Most patients who need ERCP suffer from obstructive jaundice. In the present study, the baseline of bilirubin was $118.2 \pm 117.8 \mu \mathrm{mol} / \mathrm{L}$ in the etomidate group and 108.2 $\pm 142.2 \mu \mathrm{mol} / \mathrm{L}$ in the propofol group. Patients with obstructive jaundice are more prone to develop hypotension and bradycardia during anesthesia induction and maintenance compared with non-jaundiced patients.[2,3] It was reported that patients with obstructive jaundice had decreased sensitivity in both the sympathetic and vagal components of the baroreflex.[4] Reich et al. suggested that "To avoid severe hypotension, alternatives to propofol anesthetic induction (e.g., etomidate) should be considered in patients older than $50 \mathrm{yr}$ of age with ASA physical status $\geq$ III." [26]

Myoclonus was a common side effect of etomidate for procedural sedation, which occurred in $20 \%$ to $45 \%$ of the patients in the Falk review.[8] Miner et al. noted a $20 \%$ incidence of myoclonus in their randomized clinical trial comparing etomidate with propofol.[10] In the present study, only one patient in the etomidate group experienced myoclonus, and required a brief period of mask ventilation and $50 \mathrm{mg}$ propofol (i.v.). The incidence of myoclonus in the present study was far lower than in other studies, which may be due to midazolam (2-2.5 mg i.v.) pretreatment in all patients before induction. Midazolam pretreatment reduces etomidate-induced myoclonic movements. $[27,28]$ Furthermore, in the present study, etomidate was delivered at a rate of $30 \mu \mathrm{g} \bullet \mathrm{kg}^{-1} \bullet \mathrm{min}^{-1}$ by a Graseby 3500 syringe pump. This relatively "slow" delivering speed may also reduce the incidence of myoclonus.[29]

It was reported mean aortic and left ventricular end-diastolic pressure decreased 5 and $15 \mathrm{~min}$ after midazolam, $0.2 \mathrm{mg} / \mathrm{kg}$ iv. [30] Marty et al. noted that midazolam $(0.3 \mathrm{mg} / \mathrm{kg})$ used for induction of anesthesia resulted in a transient depression of baroreflex function and a sustained decrease of sympathetic tone. [31] However, Lim et al. found that co-induction with midazolam and propofol could prevent a marked BP decrease at tracheal intubation for induc- 
tion in aged patients. [32] In the present study, the blood pressure on $\mathrm{T}_{1}$ decreased compared with $\mathrm{T}_{0}$, which may be partly attributable to small dose of midazolam (2-2.5 mg i.v.). However, because patients in both groups received the same dose of midazolam, the same effects would be expected in both groups.

Other side effects of etomidate are nausea and vomiting.[33] Vinson's study reported that $4 \%$ (5 of 134 patients) of patients experienced nausea and vomiting,[9] but in the present study, only one patient in each group experienced these side effects.

Our study had two limitations. The first is that we did not measure plasma cortisol and adrenocorticotropic hormone levels. It has been well known that adrenocortical suppression is one of the most important adverse effects of etomidate.[34] A recent paper compared much larger numbers of patients given etomidate and propofol (2616 patients were given etomidate, and 28,532 were given propofol), they found that etomidate was associated with an increased risk of 30-day mortality, cardiovascular morbidity, and prolonged hospital stay. They thought that etomidate should be used judiciously, considering that improved haemodynamic stability may be accompanied by substantially worse longer-term outcomes.[12] However, in a systematic review and meta-analysis of randomized controlled trials and observational studies, it was reported that single-dose etomidate does not increase mortality in patients with sepsis.[35] In the present study, no patient experienced adrenal crisis. There was no significant difference between groups for pancreatitis, cholangitis or sepsis after ERCP. Etomidate did not prolong hospital stay. Furthermore, there was no significant difference in the survival distributions between groups. Etomidate did not worsen longer-term outcomes. Differences in patient characteristics might contribute partly to the different results between our study and Ryu Komatsu's study: ASA I-III patients were enrolled in this study, while ASA III-IV patients were evaluated in Komatsu's study. Our data indicate that etomidate can safely be used in ASA I-III patients during ERCP.

The second limitation is that we did not measure respiratory rate, as the prone position makes it difficult to accurately count respiratory rate both artificially and automatically. In the present study, the effect on respiratory function was judged only by $\mathrm{SpO}_{2}$, which may lead to missing subclinical respiratory depression.

In conclusion, our study demonstrated that etomidate anesthesia during ERCP caused more stable haemodynamic responses compared with propofol. Etomidate is an alternative to propofol during ERCP.

\section{Acknowledgements}

The authors thank Bing $\mathrm{Hu}, \mathrm{MD}, \mathrm{PhD}$ and Fenghai $\mathrm{Yu}, \mathrm{MD}$, PhD (Endoscopy center, Eastern Hepatobiliary Surgery Hospital) for some suggestions. The authors thank Olivia Hurwitz (Department of Anesthesiology, Yale University School of Medicine) for the article revise.

\section{Funding}

This study was supported by a grant from the National Natural Science Foundation of China: (NSFC, No.81371511 and No.31171013) and B. Braun Fund for Anesthesia Scientific Research (BBF2011-007).

\section{Conflicts of Interest}

The authors declare no conflicts of interest. The study complies with current ethical consideration.

\section{References}

1. Faigel DO, Baron TH, Goldstein JL, Hirota WK, Jacobson $\mathrm{BC}$, Johanson JF, Leighton JA, Mallery JS, Peterson KA, Waring JP, Fanelli RD, Wheeler-Harbaugh J. Guidelines for the use of deep sedation and anesthesia for GI endoscopy. Gastrointest Endosc 2002; 56: 613-7.

2. Yang LQ, Song JC, Irwin MG, Song JG, Sun YM, Yu WF. A clinical prospective comparison of anesthetics sensitivity and hemodynamic effect among patients with or without obstructive jaundice. Acta anaesthesiologica Scandinavica 2010; 54: 871-7.

3. Song JG, Cao YF, Yang LQ, Yu WF, Li Q, Song JC, Fu XY, Fu Q. Awakening concentration of desflurane is decreased in patients with obstructive jaundice. Anesthesiology 2005; 102: 562-5.

4. Song JG, Cao YF, Sun YM, Ge YH, Xu XW, Yang LQ, Liu ZQ, Song SL, Yu WF. Baroreflex sensitivity is impaired in patients with obstructive jaundice. Anesthesiology 2009; 111: 561-5.

5. Davis PJ, Cook DR. Clinical pharmacokinetics of the newer intravenous anaesthetic agents. Clin Pharmacokinet 1986; 11: 18-35.

6. Möller Petrun A, Kamenik M. Bispectral index-guided induction of general anaesthesia in patients undergoing major abdominal surgery using propofol or etomidate: a double-blind, randomized, clinical trial. Br J Anaesth 2013; 110: 388-96.

7. Bendel S, Ruokonen E, Pölönen P, Uusaro A. Propofol causes more hypotension than etomidate in patients with severe aortic stenosis: a double-blind, randomized study comparing propofol and etomidate. Acta Anaesthesiol Scand 2007; 51: 284-9.

8. Falk J, Zed PJ. Etomidate for procedural sedation in the emergency department [review article]. Ann Pharmacother 2004; 38: 1272-7.

9. Vinson DR, Bradbury DR. Etomidate for procedural sedation in emergency medicine. Ann Emerg Med 2002; 39: 592-8.

10. Miner JR, Danahy M, Moch A, Biros M. Randomized clinical trial of etomidate versus propofol for procedural sedation in the emergency department. Ann Emerg Med 2007; 49: 15-22.

11. Toklu S, Iyilikci L, Gonen C, Ciftci L, Gunenc F, Sahin E, Gokel E. Comparison of etomidate-remifentanil and propofol-remifentanil sedation in patients scheduled for colonoscopy. Eur J Anaesthesiol 2009; 26: 370-6.

12. Komatsu R, You J, Mascha EJ, Sessler DI, Kasuya Y, Turan A. Anesthetic induction with etomidate, rather than propofol, is associated with increased 30-day mortality and cardiovascular morbidity after noncardiac surgery. Anesth Analg 2013; 117: 1329-37.

13. Hohl CM, Kelly-Smith $\mathrm{CH}$, Yeung TC, Sweet DD, Doyle-Waters MM, Schulzer $\mathrm{M}$. The effect of a bolus dose of etomidate on cortisol levels, mortality, and health services utilization: a systematic review. Ann Emerg Med 2010; 56: 105-13.

14. Manolaraki MM, Theodoropoulou A, Stroumpos C, Vardas E, Oustamanolakis P, Gritzali A, Chlouverakis G, Paspatis GA. Remifentanil compared with midazolam and pethidine sedation during colonoscopy: a prospective, randomized study. Dig Dis Sci 2008; 53: 34-40.

15. Lerman J. Study design in clinical research: sample size estimation and power analysis. Can J Anaesth 1996; 43: 184-91.

16. Levitt $\mathrm{C}$, Wei $\mathrm{H}$. Supraglotic pulsatile jet oxygenation and ventilation during deep propofol sedation for upper gastrointestinal endoscopy in a morbidly obese patient. J Clin Anesth 2014; 26: 157-9.

17. Angsuwatcharakon P, Rerknimitr R, Ridtitid W, Kongkam P, Poonyathawon S, Ponauthai Y, Sumdin S, Kullavanijaya P. Cocktail sedation containing 
propofol versus conventional sedation for ERCP: a prospective, randomized controlled study. BMC Anesthesiol 2012; 9: 12-20.

18. Jung M, Hofmann C, Kiesslich R, Brackertz A. Improved sedation in diagnostic and therapeutic ERCP: propofol is an alternative to midazolam. Endoscopy 2000; 32: 233-8.

19. Wehrmann T, Kokabpick S, Lembcke B, Caspary WF, Seifert H. Efficacy and safety of intravenous propofol sedation during routine ERCP: a prospective, controlled study. Gastrointest Endosc 1999; 49: 677-83.

20. Kongkam P, Rerknimitr R, Punyathavorn S, Sitthi-Amorn C, Ponauthai Y, Prempracha N, Kullavanijaya P. Propofol infusion versus intermittent meperidine and midazolam injection for conscious sedation in ERCP. J Gastrointestin Liver Dis 2008; 17: 291-7.

21. Fanti L, Agostoni M, Casati A, Guslandi M, Giollo P, Torri G, Testoni PA. Target-controlled propofol infusion during monitored anesthesia in patients undergoing ERCP. Gastrointest Endosc 2004; 60: 361-6.

22. Gillham MJ, Hutchinson RC, Carter R, Kenny GN. Patient-maintained sedation for ERCP with a target-controlled infusion of propofol: a pilot study. Gastrointest Endosc 2001; 54: 14-7.

23. Standards of Practice Committee of the American Society for Gastrointestinal Endoscopy, Lichtenstein DR, Jagannath S, Baron TH, Anderson MA, Banerjee S, Dominitz JA, Fanelli RD, Gan SI, Harrison ME, Ikenberry SO, Shen B, Stewart L, Khan K, Vargo JJ. Sedation and anesthesia in GI endoscopy [guideline]. Gastrointest Endosc 2008;68:815-26.

24. Reves JG. Intravenous Anesthetics. In Miller Rd, ed. Miller's Anesthesia. 7th ed. Philadelphia: Elsevier Churchill Livingstone 2009; Chapter 26.

25. Ebert TJ, Muzi M, Berens R, Goff D, Kampine JP. Sympathetic responses to induction of anesthesia in humans with propofol or etomidate. Anesthesiology 1992; 76: 725-33.

26. Reich DL, Hossain S, Krol M, Baez B, Patel P, Bernstein A, Bodian CA. Predictors of hypotension after induction of general anesthesia. Anesth Analg 2005; 101: 622-8.

27. Schwarzkopf KR, Hueter L, Simon M, Fritz HG. Midazolam pretreatment reduces etomidate-induced myoclonic movements. Anaesth Intensive Care 2003; 31: 18-20.

28. Hüter L, Schreiber T, Gugel M, Schwarzkopf K. Low-dose intravenous midazolam reduces etomidate-induced myoclonus: a prospective, randomized study in patients undergoing elective cardioversion. Anesth Analg 2007; 105: 1298-302.

29. Song JC, Sun YM, Zhang MZ, Yang LQ, Tao TZ, Yu WF. The etomidate requirement is decreased in patients with obstructive jaundice. Anesth Analg 2011; 113: 1028-32.

30. Marty J, Nitenberg A, Blanchet F, Zouioueche S, Desmonts JM. Effects of midazolam on the coronary circulation in patients with coronary artery disease. Anesthesiology 1986; 64: 206-10.

31. Marty J, Gauzit R, Lefevre P, Couderc E, Farinotti R, Henzel C, Desmonts JM. Effects of diazepam and midazolam on baroreflex control of heart rate and on sympathetic activity in humans. Anesth Analg 1986; 65: 113-9.

32. Lim YS, Kang DH, Kim SH, Jang TH, Kim KH, Ryu SJ, Yu SB, Kim DS. The cardiovascular effects of midazolam co-induction to propofol for induction in aged patients. Korean J Anesthesiol 2012; 62: 536-42.

33. Ruth WJ, Burton JH, Bock AJ. Intravenous etomidate for procedural sedation in emergency department patients. Acad Emerg Med 2001; 8: 13-8.

34. Wagner RL, White PF, Kan PB, Rosenthal MH, Feldman D. Inhibition of adrenal steroidogenesis by the anesthetic etomidate. N Engl J Med 1984; 310: 1415-21.

35. Gu WJ, Wang F, Tang L, Liu JC. Single-dose etomidate does not increase mortality in patients with sepsis: a systematic review and meta-analysis of randomized controlled trials and observational studies. Chest 2015; 147: $335-46$. 